\title{
Intervention for the Sake of Intervention?
}

\author{
Duncan L Hamilton ${ }^{1,2 *}$ \\ ${ }^{I}$ Consultant in Anaesthesia \& Acute Pain Medicine, James Cook University Hospital, Middlesbrough, \\ TS4 3BW, UK. ${ }^{2}$ University of Sunderland, School of Medicine, Sunderland, SRI 3SD, UK.
}

In a recent case report in this journal Mishra et al (2020) describe the use of phrenic nerve block $(\mathrm{PhNB})$ for the management of pneumothorax. ${ }^{1} \mathrm{I}$ would like to challenge the view that the pneumothorax was unequivocally caused by the conduct of a retrolaminar block (RLB) as the title of the article suggests. The authors discuss various potential causes of the pneumothorax any one of which could have been equally responsible.

Regardless of the origin of the pneumothorax, and whether or not $\mathrm{PhNB}$ is an appropriate management strategy, phrenic nerve block should not require a large volume of concentrated local anaesthetic (LA). The phrenic nerve is a small nerve that is usually visible under ultrasound as it crosses the anterior scalene muscle. It can be effectively blocked by just a few millilitres of dilute LA solution. Administering a large volume $(20 \mathrm{ml})$ of $0.5 \%$ bupivacaine, as described in the report, carries the risk of spread of LA to other vital structures in close proximity of the phrenic nerve such as the brachial plexus or recurrent laryngeal nerves. Kuusniemi and Pyylampi $^{2}$ reported partial blockade of the shoulder following PhNB with $5 \mathrm{ml}$ of $0.5 \%$ bupivacaine, while Carrero et al. (2014) reported successful ultrasound guided PhNB using just $2 \mathrm{ml}$ of $2 \%$ Lidocaine. $^{3}$

There is also an increased risk of (potentially fatal) side effects when giving an unnecessarily large volume of concentrated LA in an area where inadvertent intravascular or intrathecal injection is a possibility. While some of these

*Correspondence: Duncan L Hamilton

E mail: duncanleehamilton@nhs.net

https://orcid.org/0000-0003-2132-4867

Received: $18 / 09 / 2020$

Accepted: 04/04/2021

DOI: http:/doi.org/10.4038/slja.v29i1.8687 complications may be rare it is inappropriate to put a patient at unnecessary risk of these unwanted effects.

Furthermore, it is highly unlikely that the effects of $20 \mathrm{ml}$ of Bupivacaine placed in the vicinity of the phrenic nerve would wear off in 6 hours. It is more likely that the effects would persist anywhere from 12 to 24 hours. Yet the PhNB was repeated with a second large volume of LA ( $15 \mathrm{ml} 0.25 \%$ bupivacaine) just 6 hours following the initial PhNB. It is even possible that a large volume of injectate can result in persistent $\mathrm{PhNB}$ due to pressure ischaemia ${ }^{4}$. Thus, the routine use of large volumes of concentrated LA for PhNB cannot be advocated.

In order to maintain patient safety, it is important that new potential or actual complications from any procedure are reported. Similarly, potential newer treatments that may benefit patients should be shared. However, on the basis of this report I respectfully disagree with the authors that PhNB block appears to be successful in treating iatrogenic pneumothorax. There is no evidence to suggest that the pneumothorax of uncertain aetiology would not have resolved just as quickly without intervention.

\section{References}

1. Mishra P, Talwar P, Govil N, Parameswaran P. Phrenic nerve block, the resume management for pneumothorax after retrolaminar block. Sri Lankan Journal of Anaesthesiology. 2020; 28(2): 143-145. http://doi.org/10.4038/slja.v28i2.8516

2. Kuusniemi K, Pyylampi V. Phrenic nerve block with ultrasound-guidance for treatment of hiccups: a case report. Journal of medical case reports. 2011; 5: 493.

https://doi.org/10.1186/1752-1947-5-493

3. Carrero E, Arguis P, Sanchez M, Tercero FJ, Hurtado P, Sala X. Ultrasound-guided phrenic nerve block for CT-guided percutaneous lung biopsy. European Journal of Anesthesiology. 2014; 31: 126.

4. El-Boghdadly K, Chin KJ, Chan VWS. Phrenic Nerve Palsy and Regional Anesthesia for 
Hamilton. Sri Lankan Journal of Anaesthesiology: 29(1): 82-83 (2021)

Shoulder Surgery: Anatomical, Physiologic, and Clinical Considerations. Anesthesiology 2017;127(1):173-191.

https://doi.org/10.1097/ALN.0000000000001668 